\title{
A Review on Heat Pipe for Air Conditioning applications
}

\author{
Nikhil S. Chougule ${ }^{*}$, Tushar S. Jadhav ${ }^{\ddagger}$ and Mandar M. Lele ${ }^{\dagger}$ \\ †Department of Mechanical Engineering, MAEER's MITCOE, Pune 411038, Maharashtra, India \\ *SOPRIM, National Institute of Construction, Management and Research, Pune 411045, Maharashtra, India \\ Accepted 03 March 2016, Available online 15 March 2016, Special Issue-4 (March 2016)
}

\begin{abstract}
Heat pipe are popular in applications such as air conditioning, space technology, electronics, cooking etc. A literature review on heat pipe for air conditioning applications is conducted in the present paper. This paper focuses on the dehumidification enhancement and sensible heat recovery aspects of heat pipe heat exchanger for an air conditioning application. Based on this study, the application of a heat pipe heat exchanger in the conventional air conditioning systems is recommended as an efficient means for energy savings and dehumidification enhancement to maintain acceptable room conditions. This paper gives the idea about various parameters and methods that used for dehumidification enhancement and heat recovery application. This review concludes that, the use of heat pipe heat exchanger for heat recovery and dehumidification enhancement application makes significant changes in indoor air quality and energy consumption. So the use of HPHX is strongly recommended for Air Conditioning applications.
\end{abstract}

Keywords: Heat pipe, Air conditioning, Heat recovery, Dehumidification

\section{Introduction}

Nowadays, environment pollution and limitations in energy resources have appeared as a serious global crisis. Therefore, energy conservation and energy efficiency are necessary in all energy consuming devices including the air conditioning systems (Ehsan Firouzfar et al, 2011). As an efficient heat exchanger, heat pipe heat exchangers (HPHXs) are playing a considerable role in different fields including air conditioning systems. Heat pipes are simple heat transfer devices with high, effective thermal conductivity and the capability to transport a large amount of heat over considerable distances.

It consists of individual closed tubes that are filled with a proper working fluid. In operation, the working fluid evaporates at the evaporation section and condenses over the other end of the tube as shown in figure 1 . The condensed fluid returns back to the evaporator section through the capillary action of the wick or gravitational force in the thermosyphon heat pipes (Y. H. Yau et al, 2010). Simple design and flexibility of heat pipes are important reasons for their extensive applications in industries and air conditioning.

Presently, heat pipe heat exchangers have many applications in electronics, solar energy systems, heat recovery systems, air conditioning systems, cooling of energy storage electronic equipment, industrial applications and space apparatus etc. One of their

*Corresponding author: Nikhil S. Chougule important applications is in Air conditioning (AC) systems. The aim of AC systems is to prepare a desirable air with suitable temperature and humidity. The optimal values of these variables are varied depending on the objective of air conditioning. For example, comfort conditions for human are 22 to $25^{\circ} \mathrm{C}$ and 40 to $60 \%$ of relative humidity (ASHRAE, 1989)(Ehsan Firouzfar et al, 2011). One of the most interesting functions of HPHXs is to increase the dehumidification capacity of the conventional air conditioning systems.

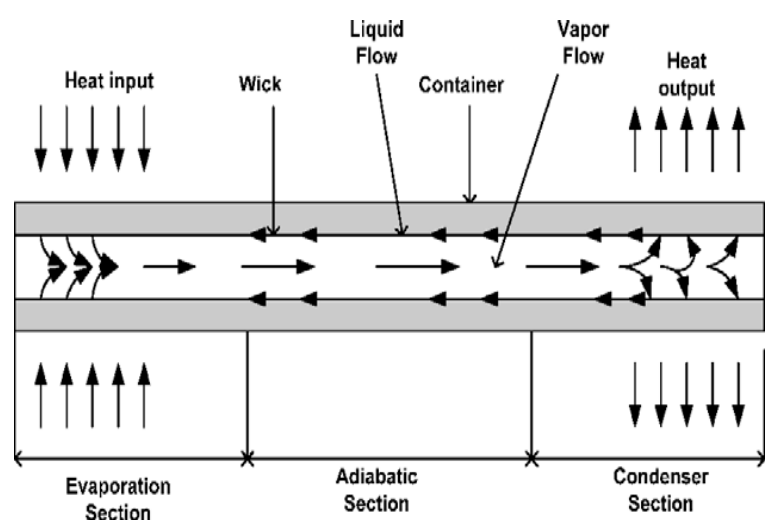

Fig.1 A schematic of heat pipe operation (Y. H. Yau, M. Ahmadzadehtalatapeh, 2010)

In air conditioning system, HPHX can be used for i) exchange of heat between fresh outdoor air and conditioned return air (heat recovery application) and 
ii) enhancing the dehumidification capability of cooling coil as well as reheat savings (dehumidification enhancement with reheat application) (T. S. Jadhav and M. M. Lele, 2015).

\section{Dehumidification enhancement with reheat application}

One of the most interesting functions of HPHXs is to increase the dehumidification capacity of the conventional air conditioning systems. In a conventional air conditioning system, the humidity is controlled by cooling the supply air stream below its dew point temperature. The cold air is then reheated to a temperature that is suitable for the conditioned space (Ehsan Firouzfar et al, 2011). The process is shown on psychometric chart in figure 2 .

Based on average ambient conditions, $32{ }^{\circ} \mathrm{C} @ 58 \%$ RH.

Cooling load - $51.3 \mathrm{~kW}$

Heating load - 7.2kW

Total load - $58.5 \mathrm{~kW}$

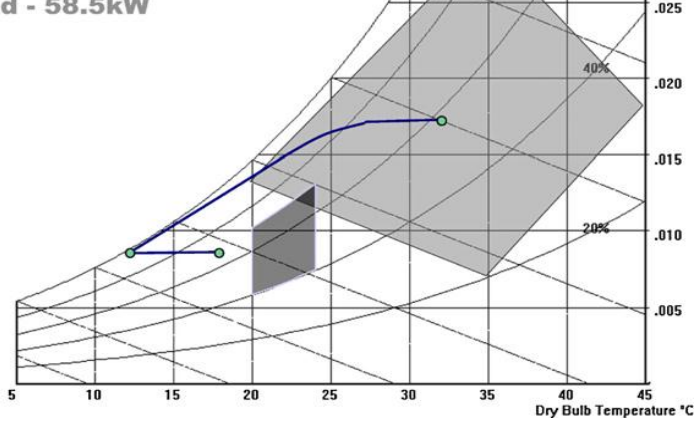

Fig.2 Simple psychometric processes for a typical HVAC system at average ambient conditions of $32{ }^{\circ} \mathrm{C}$ and 58\% (Yat H. Yau, 2007)

The drawback of this method is the cost will be increase for separate reheating process and also extra equipment and controls will have to be included.

Add in the Heat Pipe,

Heat Pipe Pre-cool - 7.2kW

Heat Pipe Re-heat - 7.2kW

New Cooling load - 44.1kW

New Heating load - 0kW

Saving 14.4kW

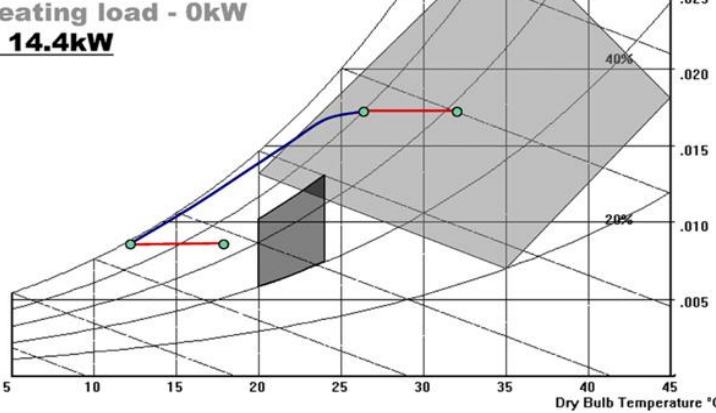

Fig.3 Simple psychometric processes for a typical HVAC system with an added HPHX at average ambient conditions of $32^{\circ} \mathrm{C}$ and $58 \%$ RH (Yat. H. Yau, 2007)

So by introducing heat pipe these drawbacks can be eliminated. By adding a heat pipe across the air stream it is possible to precool incoming air and the heat removed from the incoming air is then fed back into the outgoing air reheating it and reducing the relative humidity. Advantage of using heat pipe is precooling and reheating actions involve no additional energy usage. But it is beneficial in situation wherein reheating is necessary for maintaining required indoor conditions. The resulting energy saving is up to $30 \%$.

An experimental investigation was carried out by Yat H. Yau (2007) to determine the effect of a heat pipe heat exchanger for dehumidification enhancement in a HVAC system for tropical climates. In hot and humid tropical climates, the moisture removal capability of the chilled water coil in the HVAC systems can be enhanced if the supply air is pre-cooled before reaching the chilled water coil. For instance, a typical HVAC system at average ambient condition of $32^{\circ} \mathrm{C}$ and $58 \%$ relative humidity $(\mathrm{RH})$ with total cooling load at $58.5 \mathrm{~kW}$ as shown in Fig. 2 can save $14.4 \mathrm{~kW}$ if HPHX is added into the HVAC system as shown in Fig. 3. The experimental setup is shown in figure 4. In this research, the effect of three parameters of the inlet air state (dry-bulb temperature, relative humidity and air velocity) on the sensible heat ratio (SHR) was invested. It was observed that, i) the SHR has been reduced by the HPHX as DBT at inlet to the HPHX evaporator increased, ii) the SHR-Active Cooling and SHR-Net were reduced by the HPHX as inlet RH for HPHX evaporator increased and iii) with the exception that for mass flux at $2.2 \mathrm{kgm}^{-2} \mathrm{~s}^{-1}$, the increased mass flux has negligible influence on the SHR-AC and SHR-Net.

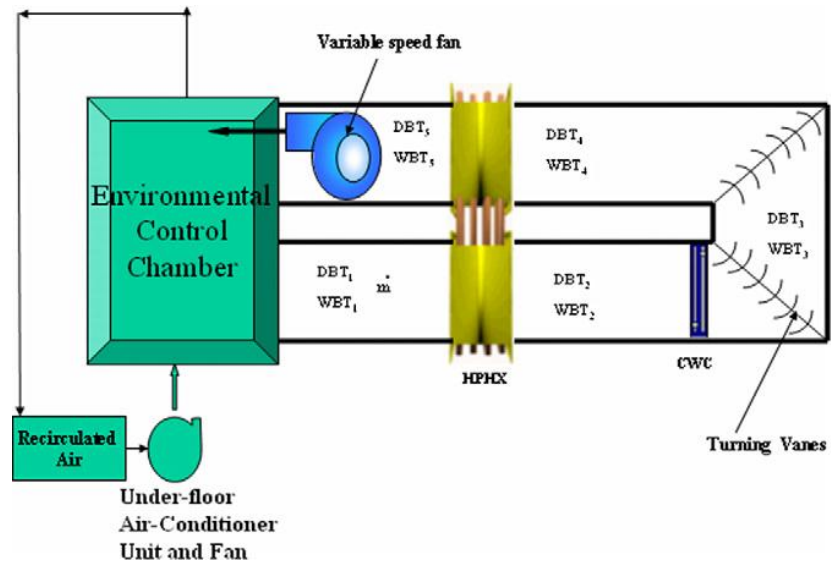

Fig.4 Schematic diagram for the experimental setup

(Yat H. Yau, 2007)

Also it was examined that, at the lowest combination of DBT and RH (i.e. $20^{\circ} \mathrm{C}$ and $50 \% \mathrm{RH}$ ), however, for all mass flow rates, SHR-Active Cooling was fairly high, ranging from 0.79 to 0.86 . On the basis of study, it is recommended that the tropical HVAC systems should be installed with heat pipe heat exchanger for dehumidification enhancement.

In another study, Mathur (2000) investigated the space humidity control with the application of a HPHEX. In this research, the influence of a six-row horizontal configuration HPHEX on the cooling and 
dehumidification capability of a $17.6 \mathrm{~kW}$ AC system was investigated. The performance of the AC system was simulated for the hot and humid climate of Southeastern United States. According to results, using the HPHEX, additional moisture of $0.134 \mathrm{~kg} / \mathrm{min}$ could be removed from the cooling coil.

Zhang et al. (2005) have proposed a fresh air processor with liquid desiccant total heat recovery in order to improve indoor air quality and decrease the energy consumption of the air conditioning system. In another research, Zhang (2006) has proposed four independent air dehumidification systems with heat recovery strategies. These systems were compared with a mechanical dehumidification system with no heat recovery. The results showed that the system of mechanical dehumidification with membrane total heat recovery consumes the least primary energy.

Recently, a performance study involving modeling and experimental of air dehumidification system combined with membrane-based total heat recovery study was carried out by Liang et al. (2010) in order to improve the efficiency of a conventional dehumidification system in hot and humid regions as shown in Figure 4. The results indicated that as compared to conventional dehumidification system, the air dehumidification rate (ADR) of the new developed system is 0.5 higher and it has the ability to perform well under harsh hot and humid weather conditions.

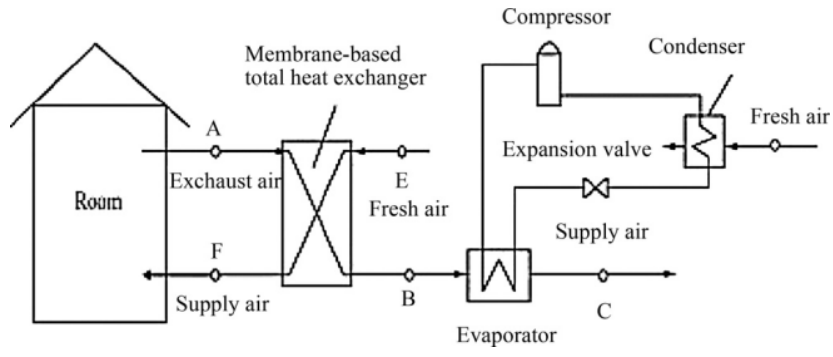

Fig. 4 Schematic of air dehumidification system combined with membrane-based total heat recovery

(Liang et al., 2010)

\section{Sensible heat recovery application}

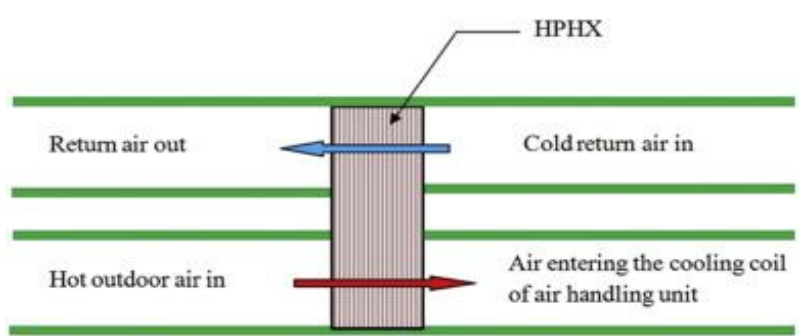

Fig.5 Sensible heat recovery in air conditioning system using HPHX (T. S. Jadhav, M. M. Lele 2015)

In air conditioning facilities with high outside air requirements such as cleanroom air conditioning systems, considerable energy savings is possible by heat recovery using heat pipe heat exchanger (HPHX).
Heat pipe heat exchanger (HPHX) is an excellent device used for heat recovery in air conditioning systems. The sensible heat recovery in air conditioning system using HPHX is shown in figure 5 . The heat is get exchanged between hot outdoor air in and cold return air in.

The possible energy savings using HPHX for heat recovery in air conditioning system for Indian climatic zones was investigated by T. S. Jadhav and M. M. Lele (2015). The analysis was carried out for 25 Indian cities representing different climatic zones. A 6 row HPHX was used for the analysis. The input parameters for the research were shown in Table 1.

Table 1 Experimental input parameters (T. S. Jadhav, M. M. Lele, 2015)

\begin{tabular}{|c|c|}
\hline Input parameters & Value \\
\hline OA quantity & $1 \mathrm{~m}^{3} / \mathrm{sec}$ \\
\hline RA $_{\text {DBT }}$ & $23{ }^{\circ} \mathrm{C}$ \\
\hline Power & $1 \mathrm{~kW} / \mathrm{TR}$ \\
\hline Plant operation & $24 \mathrm{hr}$ \\
\hline
\end{tabular}

It is revealed that, the maximum energy saving potential is for hot and dry, warm and humid and composite Indian climatic zones.

Another study was done by M. Ahmadzadehtalatapeh (2013) on an air conditioning system performance enhancement by using heat pipe base heat recovery technology. The impact of HPHX on the performance of as air conditioning system in a library building was investigated. The schematic of AC system equipped with the HPHX is shown in figure 6. In this study, HPHX with different numbers of rows were examined to determine the proper configuration. Also, TRNSYS software used to study the hourly effect of HPHX on the system in terms of energy consumption. It is concluded that, the system behavior in terms of provided air conditions is appropriate and marginally inside the comfort area with the added eight-row HPHX. It is also observed that by adding HPHX to the system significant amount of energy recovery could be achieved.

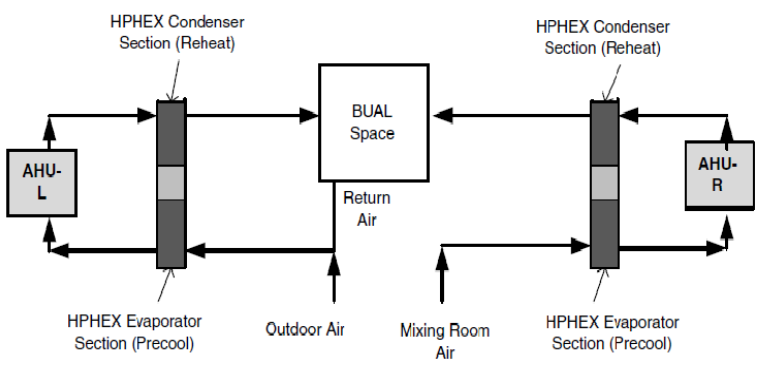

Fig.6 AC system equipped with the HPHX (M. Ahmadzadehtalatapeh, 2013)

El-Baky and Mohamed (2007) also stated that by the application of the heat pipe recovery between two streams of fresh and return air in an air conditioning system, the incoming fresh air could be cooled down.

Again, a study of window-type air conditioner with heat recovery system has been investigated by Liu et 
al. (2007) as shown in Figure 7. With the heat recovery system, they have found that the temperature of the mixed air would increase while in terms of relative humidity, would depend on the properties of the indoor air and outdoor air and their ratios.

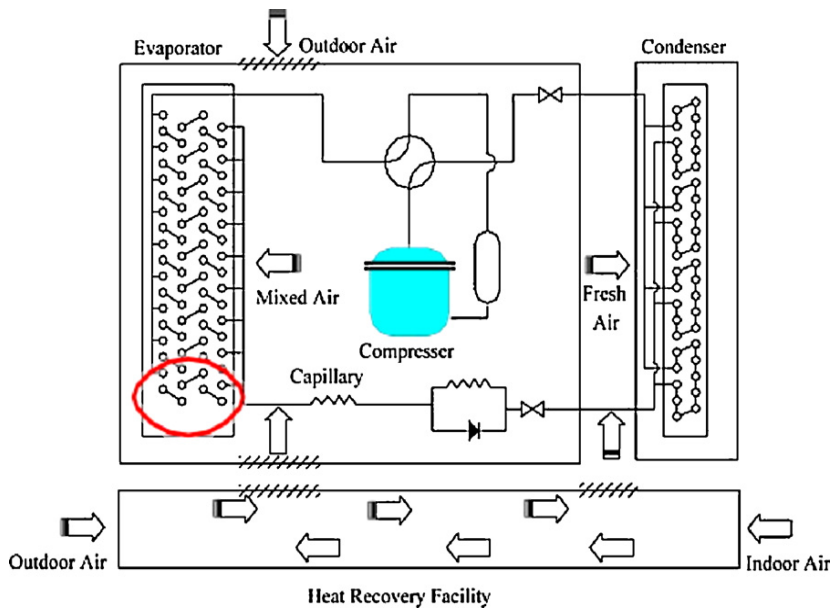

Fig.7 Schematic diagram of the window-type air conditioner with heat recovery facility (Liu X, Jiang Y et al, 2007)

A heat recovery unit was installed in study of central forced air heating and cooling system to control indoor air quality (IAQ) conducted by Persily (1982) in residential buildings. In this study, the heat recovery ventilator withdrew air from the return side of the forced-air system and replaced it with outdoor air drawn through the heat exchanger. The actual outdoor airflow rate during operation was selected to provide an air change rate of $0.35 \mathrm{~h}^{-1}$ through heat recovery system. The outcome of this study stated that the tight Miami houses met the ASHRAE minimum air change rate on the hot day but still far short on the cold days.

\section{Conclusions}

The review on the use of heat pipe for air conditioning applications shows that heat pipes are very efficient heat transfer devices which can be easily implemented as heat exchangers in air conditioning systems to ensure the energy saving and environmental protection. The literature review indicates additional thrust must be given on investigations on heat pipe for air conditioning applications by modifying heat pipe parameters such as working fluid, wick structure and geometry.

\section{References}

Ehsan Firouzfar, Mohammad Soltanieh, S. Hossien Noieand M. Hassan Saidi, (2011), Application of heat pipe heat exchangers in heating, ventilation and air conditioning (HVAC) systems, Scientific Research and Essays, Vol.6(9), pp. 1900-1908.

Y.H. Yau, M. Ahmadzadehtalatapeh, (2010), A review on the application of horizontal heat pipe heat exchangers in air conditioning systems in the tropics, Applied Thermal Engineering, 30, 77-84

G. D. Mathur, (2000), Controlling space humidity with heat pipe heat exchanger, Energy Conversion Engineering Conference and Exhibit (IECEC), Vol.2, 835-842.

Zhang LZ, Zhu DS, Deng XH, Hua B, (2005), Thermodynamic modelling of a novel air dehumidification system, Energy and Buildings, 37, 279-86.

Zhang LZ, (2006) Energy performance of independent air dehumidification systems with energy recovery measures, Energy, 31, 1228-1242.

Liang CH, Zhang LZ, Pei L-X, (2010), Performance analysis of a direct expansion air dehumidification system combined with membrane-based total heat recovery, Energy, 35, 3891-901.

Liang CH, Zhang LZ, Pei LX, (2010) Independent air dehumidification with membrane based total heat recovery, modeling and experimental validation, International Journal of Refrigeration, 33, 398-408

T. S. Jadhav, M. M. Lele, (2015), Theoretical energy saving analysis of air conditioning system using heat pipe heat exchanger for Indian climatic zones, Engineering Science and Technology, an International Journal, 18, 669-673.

Yat H. Yau, (2007), Application of a heat pipe heat exchanger to dehumidification enhancement in HVAC system for tropical climates-baseline performance characteristics study, International Journal of Thermal Sciences, 46, 164171.

M. Ahmadzadehtalatapeh, (2013), An Air-conditioning system performance enhancement by using heat pipe based heat recovery technology, Scientia Iranica, 20 (2), 329-336.

Mostafa A. Abd El-Baky, Mousa M. Mohamed, (2007) Heat pipe heat exchanger for heat recovery in air conditioning., Applied Thermal Engineering, 27, 795-801.

Liu X, Jiang Y, Xia J, Chang X. (2007), Analytical solutions of coupled heat and mass transfer processes in liquid desiccant air dehumidifier/regenerator, Energy Conversion and Management, 48, 2221-32.

Persily, (1982), Evaluation of an air-to-air heat exchanger, Environment International, 8, 453-459. 